\title{
Systematic Review and Meta-Analysis of Somatostatin Analogues in the Prevention of Postoperative Complication after Pancreaticoduodenectomy
}

\author{
Kaizhou Jin Haiyang Zhou Jian Zhang Weijun Wang Yanping Sun \\ Canping Ruan Zhiqian Hu Yi Wang
}

Department of General Surgery, Changzheng Hospital, Second Military Medical University, Shanghai, PR China

\author{
Key Words \\ Pancreaticoduodenectomy · Somatostatin · Octreotide . \\ Pancreatic fistula $\cdot$ Systematic review
}

tide had no influence on the incidence of pancreatic fistulas. High-quality RCTs assessing the role of somatostatin and pasireotide are required for further verification.

(c) 2015 S. Karger AG, Basel

\begin{abstract}
Background: The use of somatostatin analogues (SAs) following pancreaticoduodenectomy (PD) is controversial. Method: Literature databases were searched systematically for relevant articles. A meta-analysis of all randomized controlled trials (RCTs) evaluating prophylactic SAs in PD was performed. Results: Fifteen RCTs involving 1,352 patients were included. There was a towards reduced incidences of pancreatic fistulas $(p=0.26)$, clinically significant pancreatic fistulas $(p=0.08)$, and bleeding $(p=0.05)$ in prophylactic SAs group. In subgroup analyses, prophylactic somatostatin significantly reduced the incidence of pancreatic fistulas ( $p=0.02)$, with a nonsignificant trend toward reduced incidence of clinically significantly pancreatic fistulas $(p=0.06)$. Pasireotide significantly reduced the incidence of clinically significantly pancreatic fistulas $(p=0.03)$. Octreotide had no influence on the incidence of pancreatic fistulas. Conclusion: The current best evidence suggests prophylactic treatment with somatostatin or pasireotide has a potential role in reducing the incidence of pancreatic fistulas, while octreo-
\end{abstract}

\section{Introduction}

Pancreaticoduodenectomy (PD) remains a high-risk operation to this day [1]. Pancreatic fistula (PF) is the leading cause of morbidity and mortality after $\operatorname{PD}[2,3]$. To reduce the incidence of $\mathrm{PF}$, various methods have been proposed, including either technical or pharmacologic approaches [4]. Various technical improvements, such as external stent drainage of the pancreatic duct [5], pancreaticogastrostomy [6], have been successfully proven in reducing the incidence of PF after PD. However, the efficacy of somatostatin and its analogues (SAs), such as octreotide, vapreotide, and lanreotide, in prevention of PF after PD continues to be disputed.

Several randomized controlled trials (RCTs) have been conducted to address the controversy and concerns,

K.J. and H.Z. contributed equally to this work.

\section{KARGER 125}

C 2015 S. Karger AG, Base

0253-4886/15/0323-0196\$39.50/0

E-Mail karger@karger.com

www.karger.com/dsu
Zhiqian Hu or Haiyang Zhou

Department of General Surgery, Changzheng Hospital

Second Military Medical University

No. 415, Fengyang Road, Shanghai 200003 (PR China)

E-Mail czhuzq@aliyun.com or haiyang1985_1@aliyun.com 
yet the results were quite conflicting. Some studies confirmed the preventive effect; while the others did not support it. In recent years, there have been several metaanalyses that synthesized data obtained from the published RCTs to evaluate the efficacy of SAs. Nevertheless, most of the previous meta-analyses studied a mix of different pancreatic surgical procedures (PD, distal pancreatectomy, etc.) and did not evaluate the efficacy of SAs in PD specifically [7-10]. It should be noted the type of surgery could influence the rate of PF development. SAs may have different effects on different surgical procedures. Only one meta-analysis conducted 5 years ago attempted to evaluate the efficacy of SAs in preventing postoperative complication after PD [11]. However, this meta-analysis had used the inappropriate effect size (odds ratio), where the risk ratio would be more appropriate. In addition, this meta-analysis also included mixed pancreatic resection population. All of these meta-analyses were likely to introduce biases.

Although some surgical centers did not use SAs for prevention of complication after PD, SAs prophylaxis was still popular in many clinical settings [12-14]. As there is still some controversy with regard to the use of SAs in PD and several new RCTs are available, we conducted an up-to-date meta-analysis to provide the current best evidence on this topic.

\section{Methods}

\section{Identification and Selection of Studies}

Relevant studies were identified and selected by searching the databases, including: (1) Medline, Embase, Science Citation Index and Cochrane controlled trials register (updated to July 2013) under the search words 'pancreaticoduodenectomy' or 'PD' or 'pylorus-preserving pancreaticoduodenectomy' or 'PPPD', and 'somatostatin' or 'octreotide' or 'vapreotide' or 'lanreotide' or 'pasireotide', and 'randomized controlled trial' or 'RCT'. (2) A review of reference bibliographies from original research articles and reviews. No language or date limitations were imposed.

The following inclusion criteria were applied: (1) Study design: randomized controlled trials (RCTs), including multicenter trials; (2) Study population: patients undergoing PD (including PPPD); (3) SAs should be administrated as prophylaxis; (4) Each study should contain information on incidences of postoperative PF. The following exclusion criteria were applied: (1) Studies compared two groups, both submitted to SAs with different dosage or route of the same SAs, or with different SAs; (2) Comparing SAs with other prophylactic intervention; (3) Studies including mixed pancreatic resection population (PD, distal pancreatectomy and pancreaticojejunostomy), without reporting specific PD outcomes. In the case of sequential or multiple publications of analyses of the same data or overlapping data sets, the publication that reported data from the largest or most recent study was included [15].

Somatostatin Analogues for

Pancreaticoduodenectomy

\section{Data Extraction}

Data were extracted from each study by two authors (Jin and Zhou) independently according to a predesigned protocol. Following data were recorded: (1) Basic characteristics: first author, year of publication, country, number of patients in each arm, sample size, mean age, administration methods of SAs, definition of pancreatic fistula; (2) Details in study design: method of randomization, blinding (single, double or none), withdrawal and dropouts; (3) Primary outcomes: incidences of PF, incidences of clinically significant PF (defined as PF require alteration in the management of the patient), and mortality rates; (4) Secondary outcomes: incidences of abdominal infection, delayed gastric emptying, bleeding, pulmonary complication, overall complication, reoperation and length of hospital stay.

\section{Quality Assessment}

We applied the Jadad composite scale to assess the methodological quality of studies included in the meta-analysis [16]. This is a 5-point quality scale, which evaluates the studies based on perfect randomization, proper blinding, and adequate descriptions of withdrawals and dropouts. If the Jadad score of a study is more than or equal to 3, we considered it a high-quality study. Quality assessment was independently performed by two authors (Jin and Zhou). Each included study was given an overall quality score based on the Jadad composite scale. Any disagreement was resolved by discussion and consensus.

\section{Statistical Methods}

The risk ratio (RR) was used as the effect size for dichotomous data, while weighted mean difference (WMD) was used for continuous data. Summary RR (or WMD) and their corresponding $95 \%$ confidence intervals (CI) were estimated by fixed effect (Mantel-Haenszel) or random effect (DerSimonian and Laird) models $[17,18]$. Tests for heterogeneity were performed with each metaanalysis using the Cochran Q statistic and the $\mathrm{I}^{2}$ test, with $\mathrm{p}<0.05$ indicating significant heterogeneity. Random effect model was performed when heterogeneity was present. To check for publication bias, a funnel plot was constructed using Egger's linear regression method [19]. Statistical analyses were performed using Revman 5.0 and STATA 9.0 software packages. A p value $<0.05$ was considered statistically significant.

\section{Results}

\section{Characteristics of Included Studies}

1,184 records were identified by the search strategy; 1,159 records were excluded because of the reasons shown in figure 1 . Of the 25 potentially appropriate studies [20$44]$ seven were excluded for reporting no explicit outcome of PD [20-25, 27] one for duplicate publication [26] one for comparing somatostatin with octreotide [29] one for using octreotide in the control group [28]. Finally, 15 RCTs were included in the meta-analysis (table 1) [3044].

The meta-analysis involved 1,352 patients: 693 were randomized to SAs group and 659 to control group. Elev- 
Fig. 1. Flowchart of study screening according to PRISMA guidelines.

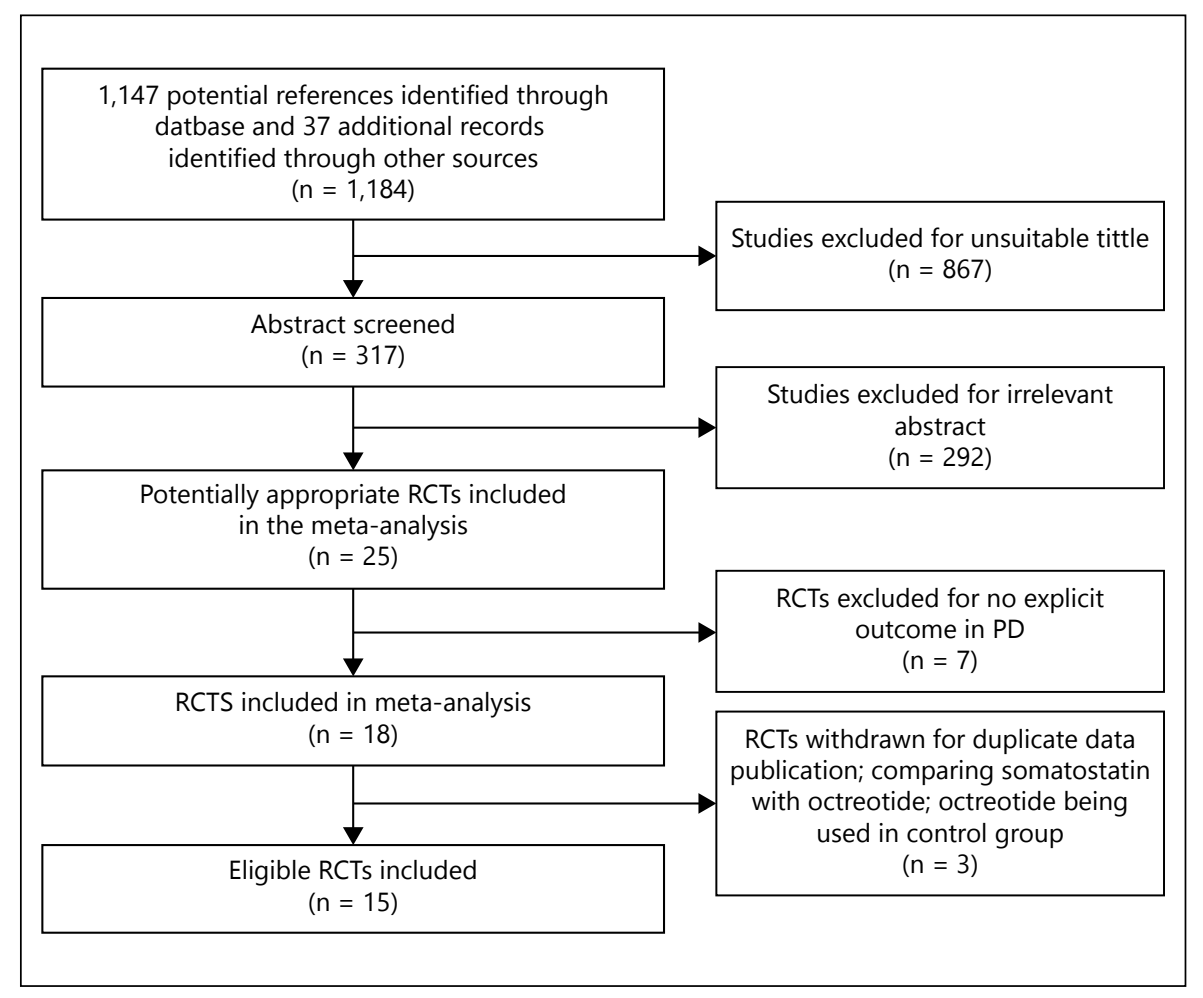

en studies were single-center trials, while the other four studies were multicenter trials. The mean age ranged from 52.5 to 69.0 years. Five studies used somatostatin, while nine studies used octreotide and one study used pasireotide. In terms of surgical approach, eight studies used classic PD, one study used PPPD in all participants, and the other studies used both PD and PPPD. Definition of PF varies among different studies (table 1). The methodological quality scores of included trials ranged from 1 to 5 (table 2).

\section{Results of Meta-Analyses}

Primary Outcomes. After pooling all the trials, $198 \mathrm{PFs}$ occurred (198/1,133, 17.5\%), 96 in the SAs group (96/583, $16.5 \%)$ and 102 in the control group (102/550, 18.5\%). The pooled RR was 0.87 (95\% CI 0.69-1.11). Eighty five clinically significant PFs occurred $(85 / 658,13.0 \%), 36$ in the SAs group (36/337, 10.7\%) and 49 in the control group (49/321, 15.3\%). The pooled RR was 0.70 (95\% CI $0.47-$ 1.05). Thirty four deaths occurred $(34 / 865,3.9 \%), 21$ in the SAs group $(21 / 442,4.8 \%)$ and 13 in the control group (13/423, 3.1\%). The pooled RR was 1.42 (95\% CI 0.762.65) (fig. 2).

Secondary Outcomes. There were no significant differences between the two groups in incidences of abdominal infection (RR 0.78, 95\% CI 0.44-1.37), delayed gastric emptying (RR 0.84, 95\% CI 0.55-1.29), bleeding (RR 0.45, 95\% CI 0.20-1.01), pulmonary complication (RR 0.90, 95\% CI 0.31-2.57), overall complication (RR $0.89,95 \%$ CI $0.71-1.11$ ) and re-operation rate (RR $1.22,95 \%$ CI $0.61-$ 2.45). In addition, there was no difference in the length of hospital stay (WMD $-1.32,95 \% \mathrm{CI}-4.22$ to 1.58 ) between the two groups (fig. 3).

\section{Subgroup Analyses}

In subgroup analyses, prophylactic somatostatin significantly reduced the incidence of pancreatic fistulas $(p=0.02)$, with a nonsignificant trend toward the reduced incidence of clinically significantly pancreatic fistulas $(p=0.06)$. Pasireotide significantly reduced the incidences of clinically significantly pancreatic fistulas $(p=0.03)$. Octreotide had no influence on the incidence of pancreatic fistulas (table 3 ).

\section{Publication Bias}

We assessed the publication bias based on the results of PF and perioperative mortality. No evidence of publication bias existed in the studies included in the metaanalysis, based on the egger's publication bias plots (fig. 4). 


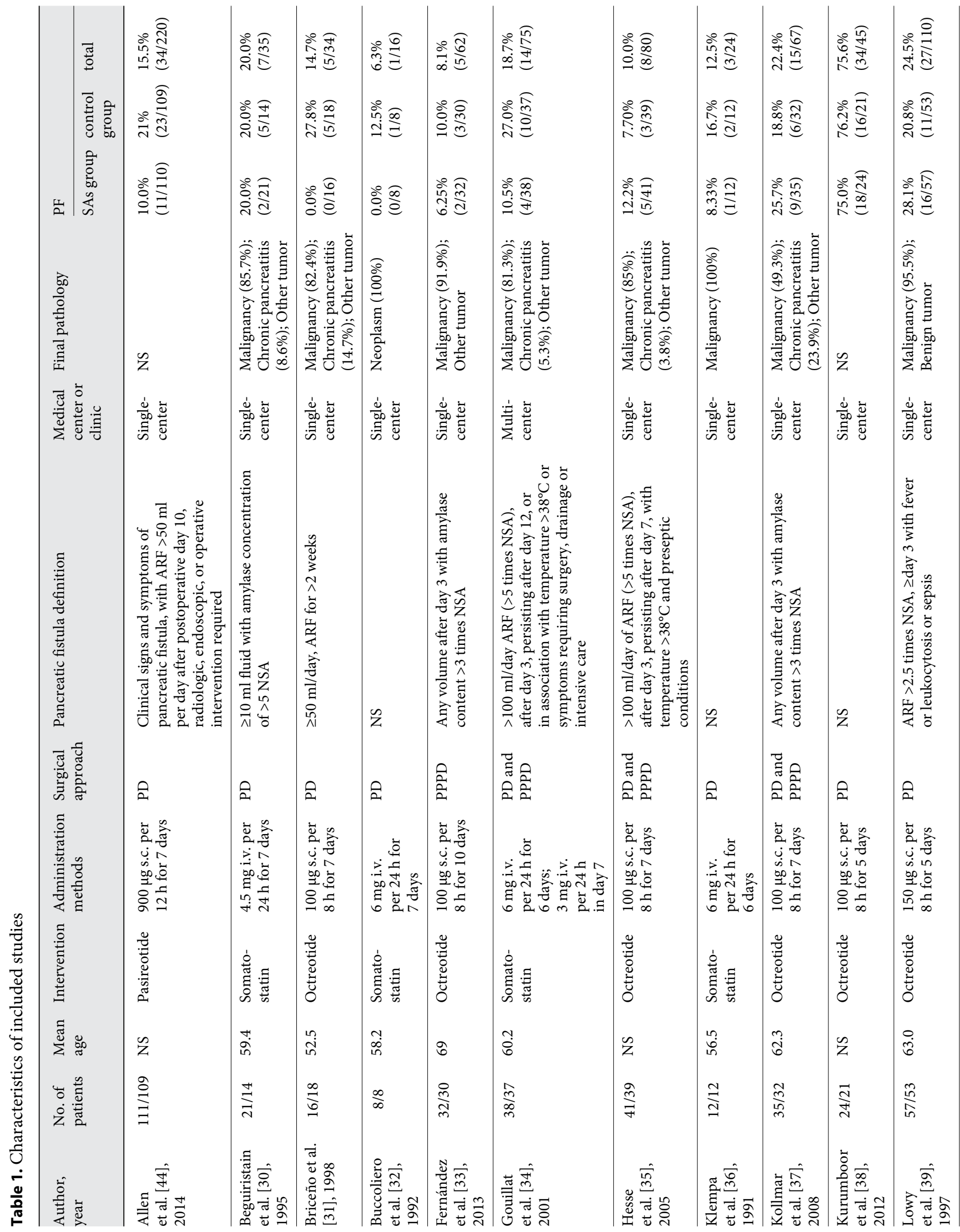




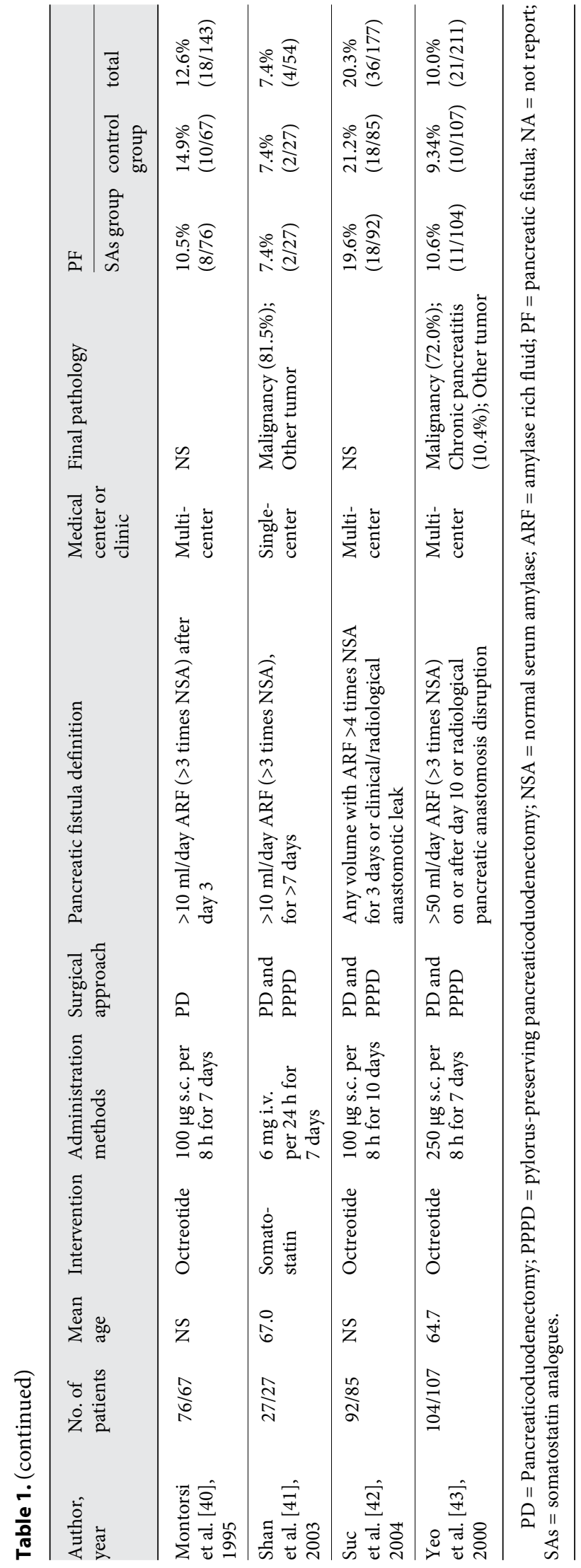

Table 2. Jadad quality score of trials included in meta-analysis

\begin{tabular}{|c|c|c|c|c|}
\hline Study & $\begin{array}{l}\text { Randomized } \\
\text { method }\end{array}$ & $\begin{array}{l}\text { Double } \\
\text { blinding }\end{array}$ & $\begin{array}{l}\text { With } \\
\text { drawals } \\
\text { dropouts }\end{array}$ & Total \\
\hline Allen et al. [44], 2014 & 2 & 2 & 1 & 5 \\
\hline \multicolumn{5}{|l|}{ Beguiristain et al. [30], } \\
\hline 1995 & 1 & 0 & 0 & 1 \\
\hline Briceño et al. [31], 1998 & 1 & 1 & 0 & 2 \\
\hline Buccoliero et al. [32], 1992 & 2 & 0 & 0 & 2 \\
\hline Fernández et al. [33], 2013 & 2 & 2 & 1 & 5 \\
\hline Gouillat et al. [34], 2001 & 2 & 2 & 1 & 5 \\
\hline Hesse et al. [35], 2005 & 2 & 0 & 0 & 2 \\
\hline Klempa et al. [36], 1991 & 0 & 1 & 0 & 1 \\
\hline Kollmar et al. [37], 2008 & 2 & 2 & 1 & 5 \\
\hline \multicolumn{5}{|l|}{ Kurumboor et al. [38], } \\
\hline 2012 & 1 & 1 & 0 & 2 \\
\hline Lowy et al. [39], 1997 & 1 & 0 & 0 & 1 \\
\hline Montorsi et al. [40], 1995 & 0 & 2 & 0 & 2 \\
\hline Shan et al. [41], 2003 & 2 & 1 & 0 & 3 \\
\hline Suc et al. [42], 2004 & 2 & 1 & 0 & 3 \\
\hline Yeo et al. [43], 2000 & 1 & 2 & 1 & 4 \\
\hline
\end{tabular}

\section{Discussion}

PF formation remains the 'Achilles heel' of PD and continues to challenge surgeons since it is the main cause of postoperative morbidity and mortality [45]. Active exocrine secretion of pancreas is considered a major factor responsible for PF development, and its inhibition holds the promise of reducing the incidence of $\mathrm{PF}$ and its associated complications after PD. SAs are known to have inhibitory effects on exocrine secretion of pancreas [46]. These drugs had been presumed to reduce the rate of PF. The concept of using SAs to prevent complication after PD was introduced by Klempa et al. [47] in 1979. Since then, several groups of investigators had evaluated the administration of SAs for the prevention of complications after PD. Yet the results were quite conflicting. As there is still no definitive conclusion on this issue, it may be particularly germane to do such a systematic review to resolve this problem that is frequently encountered in the surgical community.

The main finding of our meta-analysis was that prophylactic treatment with somatostatin or pasireotide have a potential role in reducing the incidence of pancreatic fistulas, while octreotide had no influence on the incidence of pancreatic fistulas. It is worth noting that pasireotide has a longer half-life and a broader binding profile, decreases pancreatic exocrine secretions, and can be used for the prevention of postoperative pancreatic fistulas [48]. 
a Pancreatic fistula

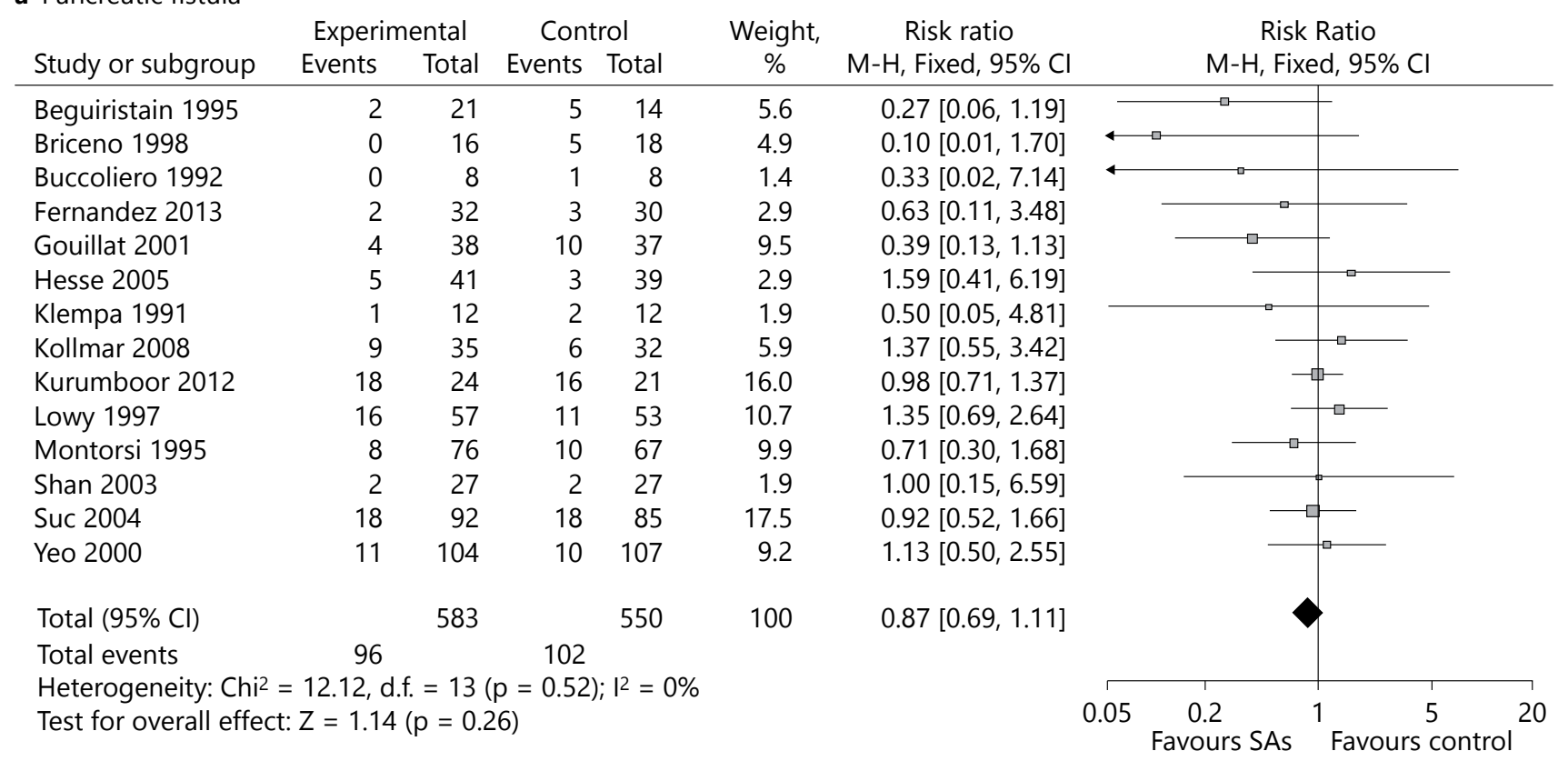

b Clinically significant pancreatic fistula

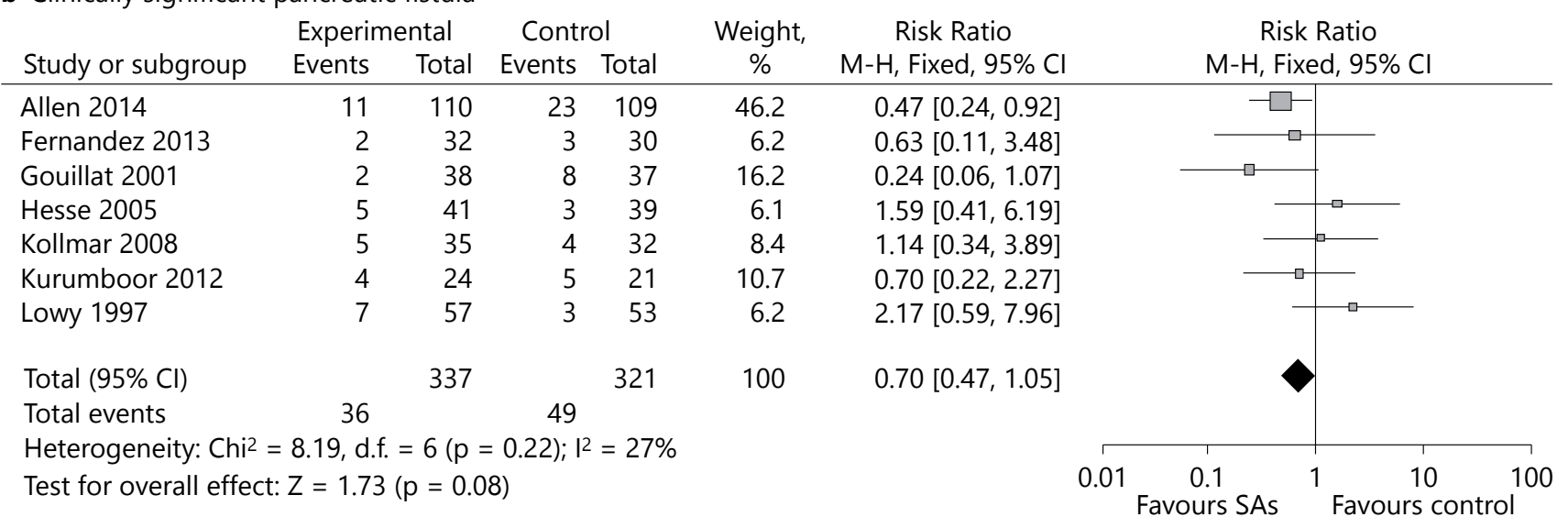

Fig. 2. Forest plot - somatostatin and its analogues vs. no intervention. Primary outcome: pancreatic fistula (a), clinically significant pancreatic fistula (b), perioperative mortality $(\mathbf{c})$.

(For figure $2 c$ see next page.)

However, before drawing a conclusion, there are still lots of things we need to reconsider. First of all, although there was no statistical heterogeneity among included studies (except for length of hospital stay), we could not exclude the potential clinical heterogeneity. In fact, there was a wide variability in reported rates of PF after PD among included studies, with the rates of PF ranging from 6.2 to $75.6 \%$ and the rates of clinically significant PF ranging from 8.1 to $20.0 \%$. An important source of clinical heterogeneity may come from the variability in definition of PF. A more strict definition may result in a higher rate of $\mathrm{PF}$, while a more compromised definition may lead to a lower rate of PF [49]. The same is true for clinically significant PF. The definition of clinically 
c Perioperative mortality

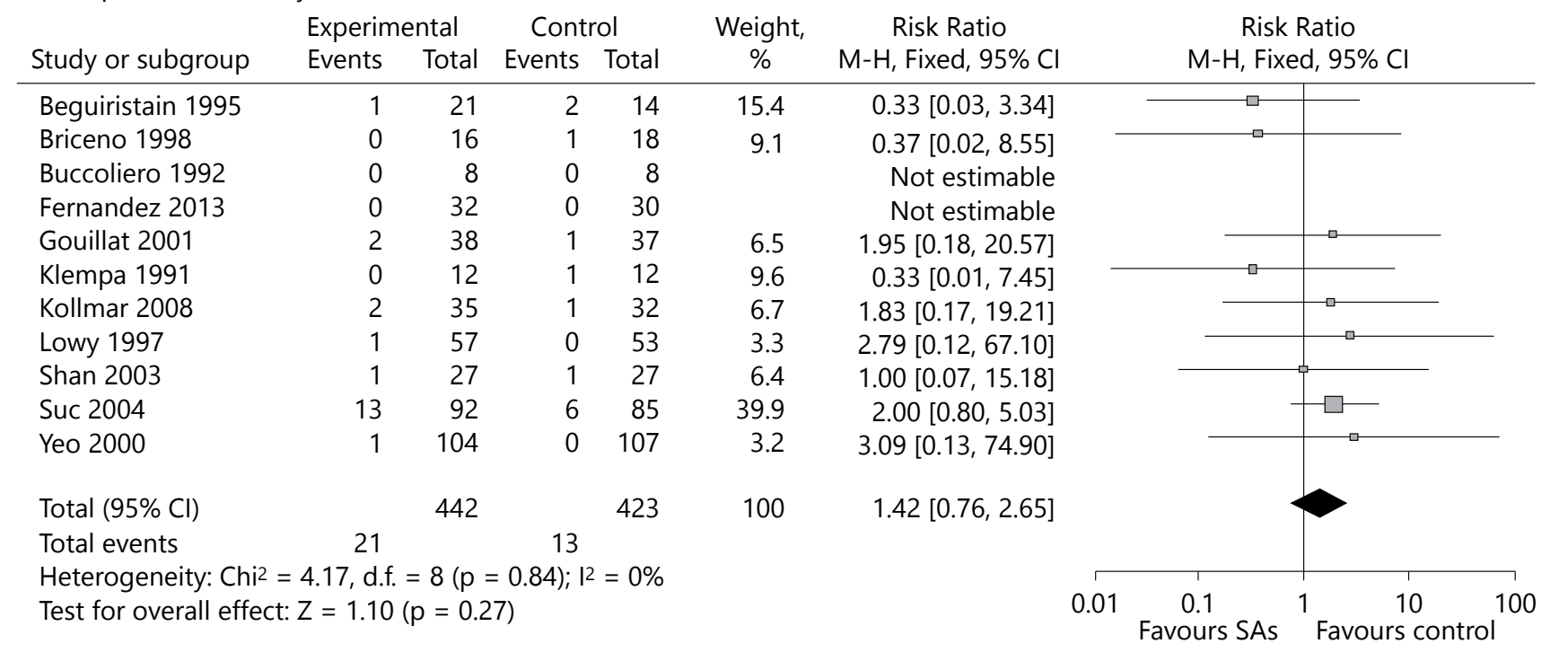

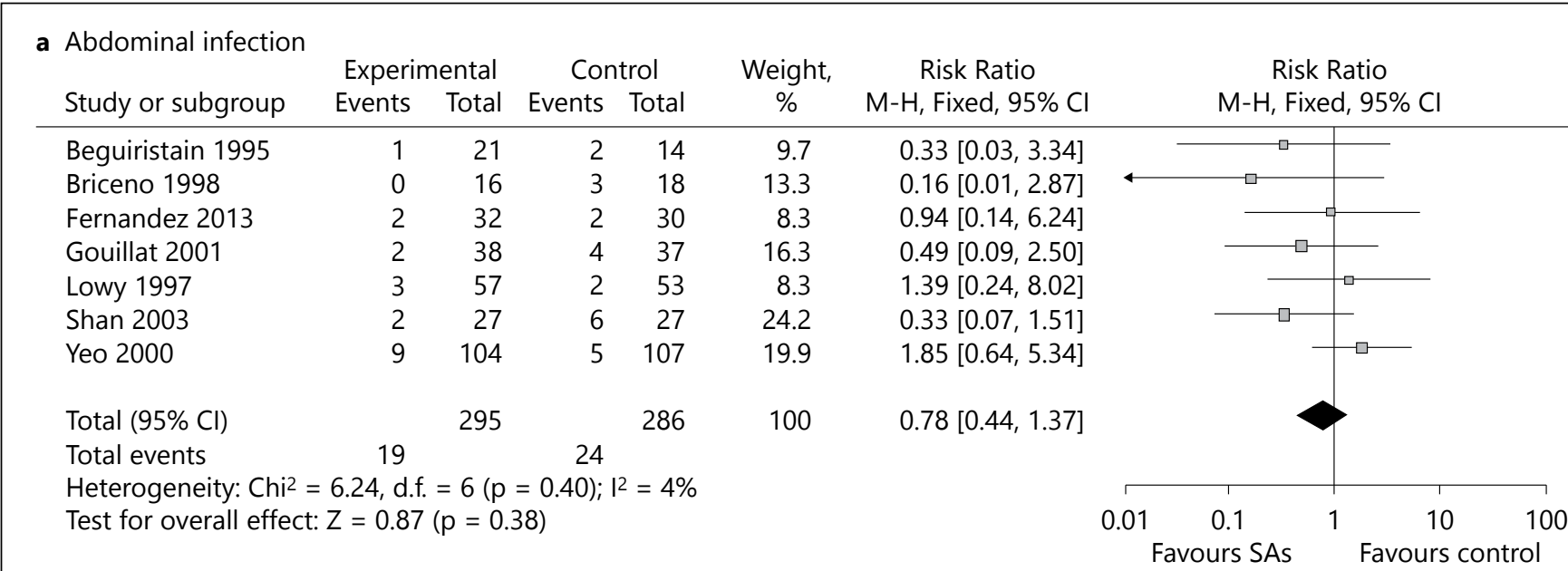

b Delayed gastric emptying

Study or subgroup Events Total Events Total

Weight, Risk Ratio

Risk Ratio

Beguiristain 1995

Fernandez 2013

Kollmar 2008

Shan 2003

Yeo 2000

$2 \quad 21$

$4 \quad 14$

$\%$

$\mathrm{M}-\mathrm{H}$, Fixed, 95\% Cl

$\mathrm{M}-\mathrm{H}$, Fixed, 95\% Cl

Total $(95 \% \mathrm{Cl})$

432

430

$0.33[0.07,1.58]$

$7 \quad 35$

$\begin{array}{llll}11 & 27 & 10 & 27\end{array}$

632

11.5

$0.94[0.26,3.42]$

$1.07[0.40,2.84]$

$1.10[0.56,2.15]$

$0.65[0.26,1.62]$

Total events

219

$219 \quad 210$

30.1

$0.84[0.55,1.29]$

Heterogeneity: $\mathrm{Chi}^{2}=2.52$, d.f. $=4(p=0.64) ; \mathrm{I}^{2}=0 \%$

Test for overall effect: $Z=0.80(p=0.42)$

100

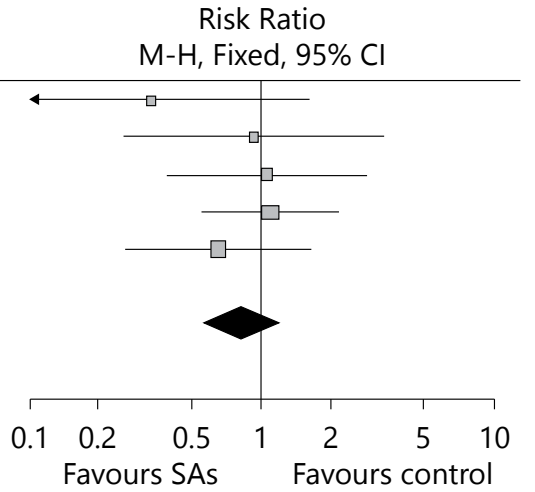

Fig. 3. Forest plot - somatostatin and its analogues vs. no intervention. Secondary outcome: abdominal infection (a), delayed gastric emptying (b). 
c Bleeding

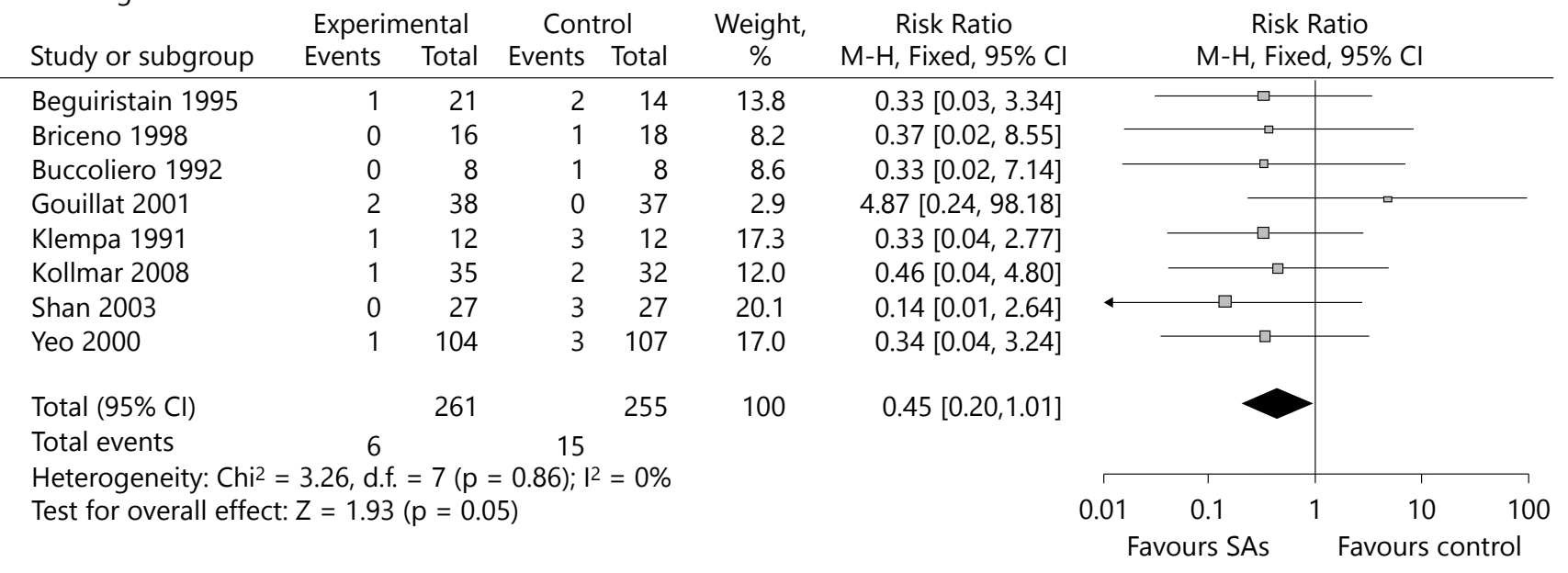

d Plumonary complication

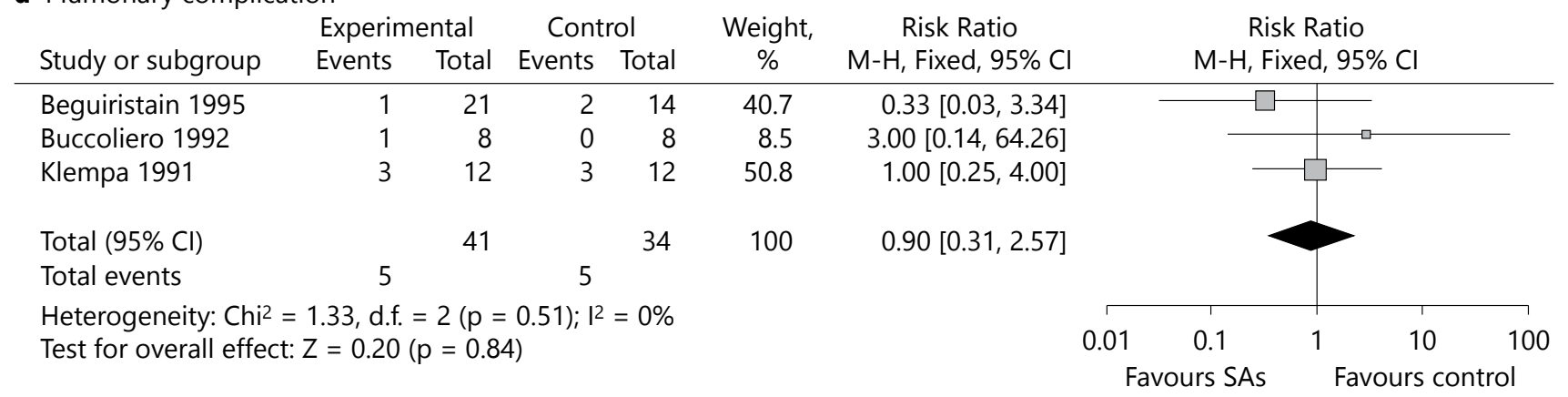

e Overall complication

Experimental Control Weight, Risk Ratio Study or subgroup Events Total Events Total

$\begin{array}{lllll}\text { Briceno } 1998 & 2 & 16 & 7 & 18\end{array}$

Fernandez 2013

Gouillat 2001

Klempa 1991

Kurumboor 2012

Lowy 1997

Shan 2003

Yeo 2000

Total $(95 \% \mathrm{Cl})$

$\begin{array}{rrrr}10 & 32 & 11 & 30\end{array}$

$\mathrm{M}-\mathrm{H}$, Fixed, 95\% C

Risk Ratio

$6.10 .32[0.08,1.33]$

10.6

$0.85[0.42,1.71]$

$0.60[0.28,1.28]$

$0.50[0.16,1.55]$

$0.88[0.37,2.09]$

$1.22[0.66,2.26]$

$0.50[0.24,1.04]$

$1.20[0.84,1.71]$

Total events

107

Heterogeneity: Chi $^{2}=10.16$, d.f. $=7(p=0.18) ;\left.\right|^{2}=31 \%$

Test for overall effect: $Z=1.05(p=0.29)$

$0.89[0.71,1.11]$

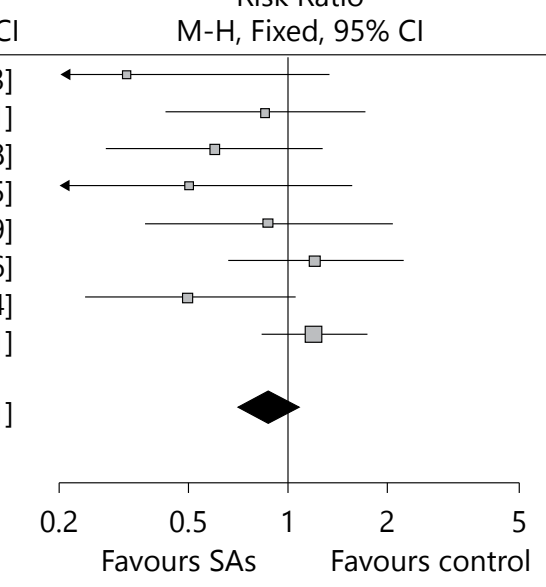

Fig. 3. Forest plot - somatostatin and its analogues vs. no intervention. Secondary outcome: bleeding (c), pulmonary complication $(\mathbf{d})$, overall complication $(\mathbf{e})$. 


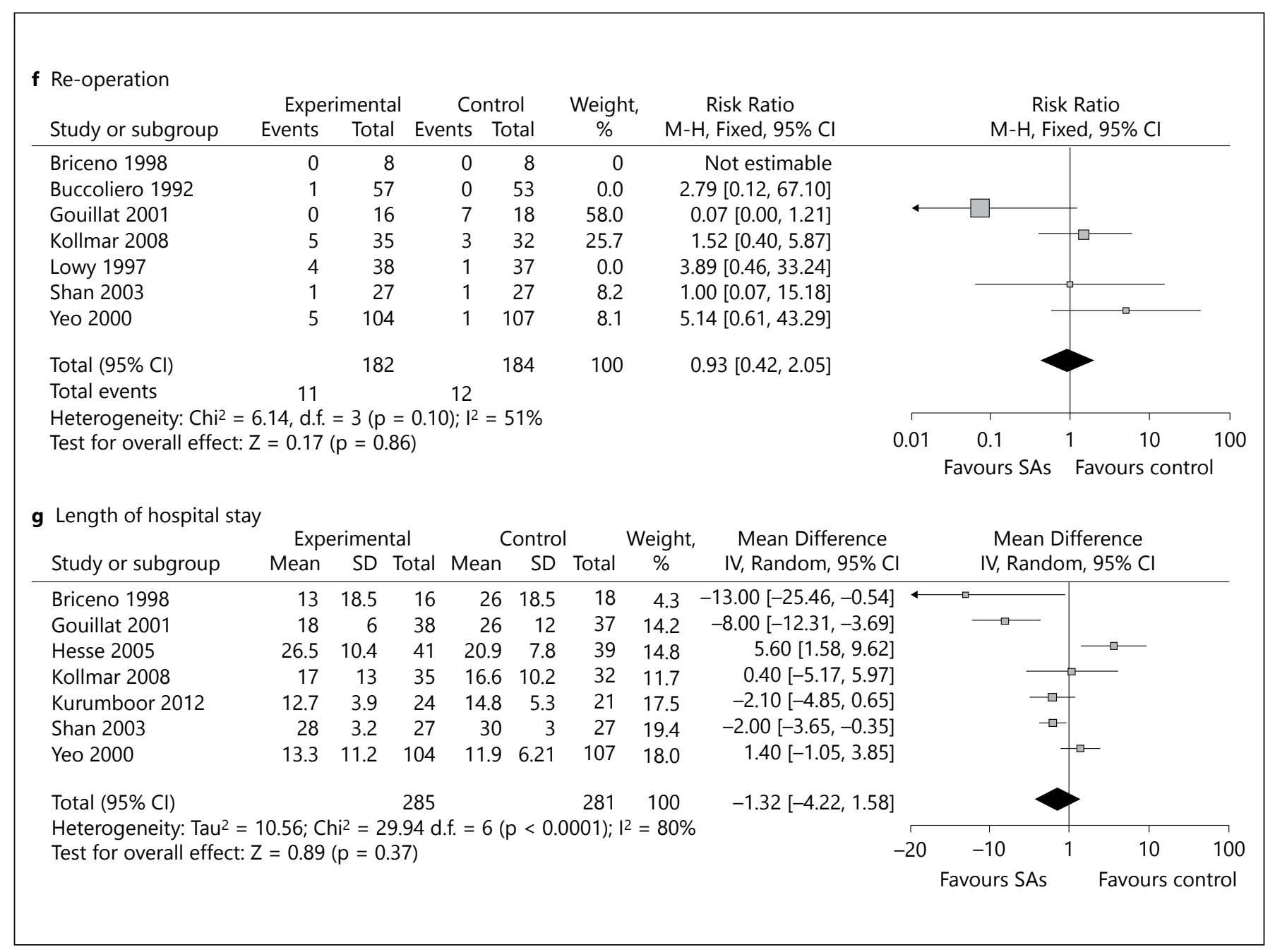

Fig. 3. Forest plot - somatostatin and its analogues vs. no intervention. Secondary outcome: re-operation (f), length of hospital stay $(\mathbf{g})$.

Table 3. Subgroup analyses: comparison of somatostatin analogues vs. no intervention in outcomes

\begin{tabular}{|c|c|c|c|c|c|c|c|c|c|c|}
\hline $\begin{array}{l}\text { Somatostatin } \\
\text { analogue }\end{array}$ & Outcome & $\begin{array}{l}\text { No. of } \\
\text { study }\end{array}$ & events & total & events & total & $\begin{array}{l}\text { Analysis } \\
\text { mode }\end{array}$ & $\begin{array}{l}\text { Pooled effects } \\
\text { (95\% CI) }\end{array}$ & $\begin{array}{l}\text { Test for heterogeneity, } \\
\text { Chi-square test }(p)\end{array}$ & $\begin{array}{l}Z \text { test for } \\
\text { pooled } \\
\text { effect size }(p)\end{array}$ \\
\hline Somatostatin & Clinically significant PF & 1 & 2 & 38 & 8 & 37 & Fixed & $0.24(0.06-1.07)$ & & $1.87(0.06)$ \\
\hline Octreotide & $\mathrm{PF}$ & 9 & 87 & 477 & 82 & 452 & Fixed & $0.99(0.76-1.27)$ & $5.31(0.72)$ & $0.11(0.91)$ \\
\hline Pasireotide & Clinically significant PF & 1 & 11 & 110 & 23 & 109 & Fixed & $0.47(0.24-0.92)$ & - & $2.19(0.03)$ \\
\hline
\end{tabular}

$\mathrm{CI}=$ Confidence interval; $\mathrm{PF}=$ pancreatic fistula 


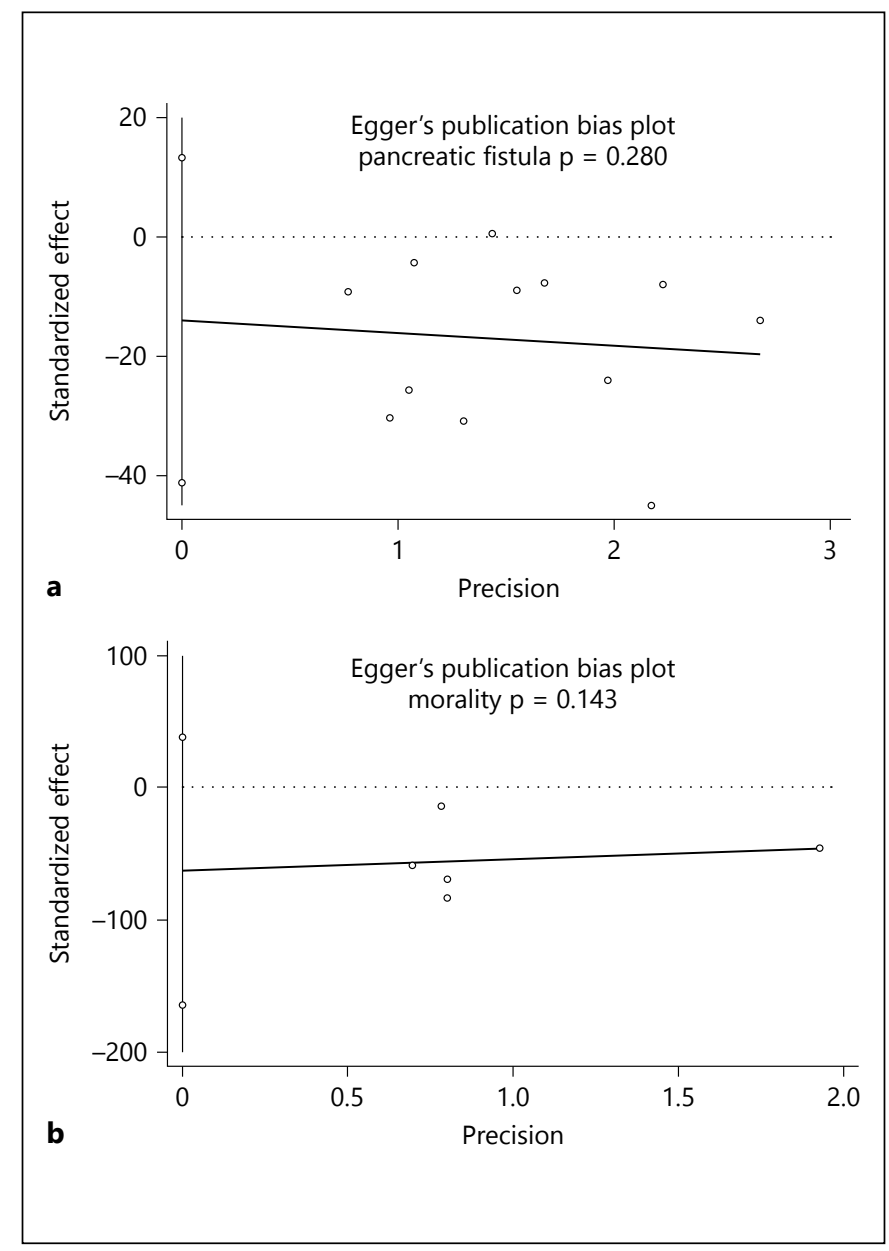

Fig. 4. Egger's publication bias plots - pancreatic fistula rates (a), perioperative mortality rates $(\mathbf{b})$.

significant PF lacks uniform definition before the ISGPF definition in 2005 [50]. Another source of clinical heterogeneity may be attributed to the differences in inclusion criteria. Some included studies did not recruit chronic pancreatitis patients, while the others recruited a large number of chronic pancreatitis patients. It is well known that patients who underwent PD for chronic pancreatitis have lower rates of PF, compared with patients who underwent PD for malignancy. Furthermore, PD for different malignancies may also result in different outcomes. However, given the limitation of the trials included, it is impossible to analyze these factors independently.

Last but not the least, the different rates of PF among included studies may be attributed to the surgical technique and experience of different surgeons, which were often ignored. Notably, delicate surgical technique and

Somatostatin Analogues for

Pancreaticoduodenectomy other non-pharmacologic prophylactic procedures were more important because major complications, such as $\mathrm{PF}$, were usually related to technical pitfalls. The outcome of PD is dependent on surgical experience and hospital volume [51]. To reduce the morbidity and mortality after $\mathrm{PD}$, a policy of centralization may therefore be appropriate [52].

Patient-derived risk factors of PF after PD included soft pancreatic texture, small pancreatic duct and poor blood supply [53, 54]. These patients were clarified as high-risk. Some surgeons believed that the high-risk patients who underwent PD would benefit from prophylatic SA [12-14]. Unfortunately, a subgroup meta-analysis of high-risk patients cannot be performed because of limited data. However, the studies of Lowy et al. [39], Yeo et al. [43], and Shan et al. [41] showed that SAs could not reduce the rate of $\mathrm{PF}$ and other complications in patients at high-risk after PD. In addition, Fernández-Cruz et al. [33] further demonstrated no significant differences in median pancreatic juice output were found between SAs and placebo groups in high-risk patients (with a pancreatic duct diameter $<5 \mathrm{~mm}$ ). Thus, there is no solid evidence that SAs would reduce PF after PD in high-risk patients.

SAs seemed to be well-tolerated, and the adverse effects associated with the intervention were mainly minor adverse effects, such as pain at the injection site. However, downregulation of digestive enzyme secretion by SAs could contribute to the prolonged time to resume intestinal transit and increase delayed gastric emptying [26]. Furthermore, prophylactic SAs were usually used for 6 or 7 days in the included trials, and the high cost was a big concern.

It is possible that unpublished articles, such as scientific dissertations, may be missed because only published studies can be involved in the meta-analysis. However, by constructing funnel plots by Egger's linear regression methods, we found no publication bias.

In conclusion, the current best available evidence suggests prophylactic treatment with somatostatin or pasireotide have a potential role in reducing incidence of pancreatic fistulas, while octreotide had no influence on the incidence of pancreatic fistulas. High-quality RCTs assessing the role of somatostatin and pasireotide are required for further verification.

\section{Acknowledgment}

Declaration of Personal Interests: None. 


\section{Funding}

This work was supported by the National Natural Science Foundation of China (No. 31100681), Shanghai nanotechnology program (11nm0504800) and Shanghai Rising Star Program (No. 11CG42).

\section{Disclosure Statement}

None declared.

\section{Author Contribution}

Kaizhou Jin, Haiyang Zhou and Zhiqian Hu designed study. Kaizhou Jin and Haiyang Zhou collected and analyzed data. Kaizhou Jin and Haiyang Zhou wrote the draft. Jian Zhang, Weijun Wang, Yanping Sun, Canping Ruan, Yi Wang and Zhiqian $\mathrm{Hu}$ revised it critically. All the authors approved the version to be published.

\section{References}

-1 Are C, Dhir M, Ravipati L: History of pancreaticoduodenectomy: early misconceptions, initial milestones and the pioneers. $\mathrm{HPB}(\mathrm{Ox}-$ ford) 2011;13:377-384.

$\checkmark 2$ Denbo JW, Orr WS, Zarzaur BL, Behrman SW: Toward defining grade $\mathrm{C}$ pancreatic fistula following pancreaticoduodenectomy: incidence, risk factors, management and outcome. HPB (Oxford) 2012;14:589-593.

-3 Ramacciato G, Mercantini P, Petrucciani N, et al: Risk factors of pancreatic fistula after pancreaticoduodenectomy: a collective review. Am Surg 2011;77:257-269.

4 Lai EC, Lau SH, Lau WY: Measures to prevent pancreatic fistula after pancreatoduodenectomy: a comprehensive review. Arch Surg 2009; 144:1074-1080.

$>5$ Motoi F, Egawa S, Rikiyama T, Katayose Y, Unno M: Randomized clinical trial of external stent drainage of the pancreatic duct to reduce postoperative pancreatic fistula after pancreaticojejunostomy. Br J Surg 2012;99: 524-531.

6 Topal B, Fieuws S, Aerts R, et al: Pancreaticojejunostomy versus pancreaticogastrostomy reconstruction after pancreaticoduodenectomy for pancreatic or periampullary tumours: a multicentre randomised trial. Lancet Oncol 2013;14:655-662.

7 Li-Ling J, Irving M: Somatostatin and octreotide in the prevention of postoperative pancreatic complications and the treatment of enterocutaneous pancreatic fistulas: a systematic review of randomized controlled trials. $\mathrm{Br}$ J Surg 2001;88:190-199.

$>8$ Connor S, Alexakis N, Garden OJ, Leandros E, Bramis J, Wigmore SJ: Meta-analysis of the value of somatostatin and its analogues in reducing complications associated with pancreatic surgery. Br J Surg 2005;92:1059-1067.

$>9$ Alghamdi AA, Jawas AM, Hart RS: Use of octreotide for the prevention of pancreatic fistula after elective pancreatic surgery: a systematic review and meta-analysis. Can J Surg 2007;50:459-466

$>10$ Gurusamy KS, Koti R, Fusai G, Davidson BR: Somatostatin analogues for pancreatic surgery. Cochrane Database Syst Rev 2012 6:CD008370.
11 Zeng Q, Zhang Q, Han S, et al: Efficacy of somatostatin and its analogues in prevention of postoperative complications after pancreaticoduodenectomy: a meta-analysis of randomized controlled trials. Pancreas 2008;36: 18-25.

12 Gaujoux S, Cortes A, Couvelard A, et al: Fatty pancreas and increased body mass index are risk factors of pancreatic fistula after pancreaticoduodenectomy. Surgery 2010;148:1523.

13 Tranchart H, Gaujoux S, Rebours V, et al: Preoperative CT scan helps to predict the occurrence of severe pancreatic fistula after pancreaticoduodenectomy. Ann Surg 2012;256: 139-145.

14 El Nakeeb A, Salah T, Sultan A, et al: Pancreatic anastomotic leakage after pancreaticoduodenectomy. Risk factors, clinical predictors, and management (single center experience). World J Surg 2013;37:1405-1418.

15 Little J, Bradley L, Bray MS, et al: Reporting, appraising, and integrating data on genotype prevalence and gene-disease associations. Am J Epidemiol 2002;156:300-310.

16 Jadad AR, Moore RA, Carroll D, et al: Assessing the quality of reports of randomized clinical trials: is blinding necessary? Control Clin Trials 1996;17:1-12.

17 Shadish WR, Haddock CK: Combining estimates of effect size; in Cooper H, Hedges LV (eds): The Handbook of Research Synthesis. New York, Russel Sage Foundation, 1994, pp 261-281.

18 DerSimonian R, Laird N: Meta-analysis in clinical trials. Control Clin Trials 1986;7:177188.

19 Egger M, Davey Smith G, Schneider M, Minder C: Bias in meta-analysis detected by a simple, graphical test. BMJ 1997;315:629-634.

20 Lange JR, Steinberg SM, Doherty GM, et al: A randomized, prospective trial of postoperative somatostatin analogue in patients with neuroendocrine tumors of the pancreas. Surgery 1992;112:1033-1037; discussion 10371038.

21 Büchler M, Friess H, Klempa I, et al: Role of octreotide in the prevention of postoperative complications following pancreatic resection.
Am J Surg 1992;163:125-130; discussion 130131.

22 Tulassay Z, Flautner L, Sándor Z, Fehérvári I: Perioperative use of somatostatin in pancreatic surgery. Acta Biomed Ateneo Parmense 1993;64:205-211.

23 Pederzoli P, Bassi C, Falconi M, Camboni MG: Efficacy of octreotide in the prevention of complications of elective pancreatic surgery. Italian Study Group. Br J Surg 1994;81:265-269.

24 Friess H, Büchler MW: Efficacy of somatostatin and its analogues in pancreatic surgery and pancreatic disorders. Digestion 1996; 57(suppl 1):97-102.

25 Sarr MG: The potent somatostatin analogue vapreotide does not decrease pancreas-specific complications after elective pancreatectomy: a prospective, multicenter, double-blinded, randomized, placebo-controlled trial. J Am Coll Surg 2003;196:556-564; discussion 564-565; author reply 565.

26 Shan YS, Sy ED, Tsai ML, Tang LY, Li PS, Lin PW: Effects of somatostatin prophylaxis after pylorus-preserving pancreaticoduodenectomy: increased delayed gastric emptying and reduced plasma motilin. World J Surg 2005; 29:1319-1324.

27 Ramos-De la Medina A, Sarr MG: Somatostatin analogues in the prevention of pancreasrelated complications after pancreatic resection. J Hepatobiliary Pancreat Surg 2006;13: 190-193.

28 Wang W, Tian B, Babu SR, Zhang Y, Yang M: Randomized, placebo-controlled study of the efficacy of preoperative somatostatin administration in the prevention of postoperative complications following pancreaticoduodenectomy. Hepatogastroenterology 2013;60: 400-405.

29 Closset J, Journe S, Mboti F, El Nakadi I, Gelin $\mathrm{M}$ : Randomized controlled trial comparing somatostatin with octreotide in the prevention of complications after pancreatectomy. Hepatogastroenterology 2008;55:1818-1823.

30 Beguiristain A, Espí A, Balen E, Pardo F, Hernández Lizoaín JL, Alvarez Cienfuegos J: [Somatostatin prophylaxis following cephalic duodenopancreatectomy]. Rev Esp Enferm Dig 1995;87:221-224. 
31 Briceño Delgado FJ, López Cillero P, Rufián Peña S, Solórzano Peck G, Miño Fugarolas G, Pera Madrazo C: [Prospective and randomized study on the usefulness of octreotide in the prevention of complications after cephalic duodeno-pancreatectomy]. Rev Esp Enferm Dig 1998;90:687-694.

32 Buccoliero F, Pansini GC, Mascoli F, Mari C, Donini A, Navarra G: [Somatostatin in duodenocephalopancreatectomy for neoplastic pathology]. Minerva Chir 1992;47:713-716.

33 Fernández-Cruz L, Jiménez Chavarría E, Taurà $\mathrm{P}$, Closa $\mathrm{D}$, Boado $\mathrm{MA}$, Ferrer J: Prospective randomized trial of the effect of octreotide on pancreatic juice output after pancreaticoduodenectomy in relation to histological diagnosis, duct size and leakage. HPB (Oxford) $2013 ; 15: 392-399$.

34 Gouillat C, Chipponi J, Baulieux J, Partensky C, Saric J, Gayet B: Randomized controlled multicentre trial of somatostatin infusion after pancreaticoduodenectomy. Br J Surg 2001; 88:1456-1462.

35 Hesse UJ, DeDecker C, Houtmeyers P, et al: Prospectively randomized trial using perioperative low-dose octreotide to prevent organrelated and general complications after pancreatic surgery and pancreatico-jejunostomy. World J Surg 2005;29:1325-1328.

- 36 Klempa I, Baca I, Menzel J, Schuszdiarra V: [Effect of somatostatin on basal and stimulated exocrine pancreatic secretion after partial duodenopancreatectomy. A clinical experimental study]. Chirurg 1991;62:293299.

37 Kollmar O, Moussavian MR, Richter S, de Roi $\mathrm{P}$, Maurer CA, Schilling MK: Prophylactic octreotide and delayed gastric emptying after pancreaticoduodenectomy: results of a prospective randomized double-blinded placebo-controlled trial. Eur J Surg Oncol 2008;34: 868-875.
38 Kurumboor P, Kamalesh NP, Pramil K, Vipin IS, Shylesh A, Varma D, et al: A prospective randomized controlled trial on use of octreotide in patients with soft pancreas undergoing pancreaticoduodenectomy: interim analysis. HPB (Oxford) 2012;14:225.

39 Lowy AM, Lee JE, Pisters PW, et al: Prospective, randomized trial of octreotide to prevent pancreatic fistula after pancreaticoduodenectomy for malignant disease. Ann Surg 1997; 226:632-641.

40 Montorsi M, Zago M, Mosca F, et al: Efficacy of octreotide in the prevention of pancreatic fistula after elective pancreatic resections: a prospective, controlled, randomized clinical trial. Surgery 1995;117:26-31.

41 Shan YS, Sy ED, Lin PW: Role of somatostatin in the prevention of pancreatic stump-related morbidity following elective pancreaticoduodenectomy in high-risk patients and elimination of surgeon-related factors: prospective, randomized, controlled trial. World J Surg 2003;27:709-714

42 Suc B, Msika S, Piccinini M, et al: Octreotide in the prevention of intra-abdominal complications following elective pancreatic resection: a prospective, multicenter randomized controlled trial. Arch Surg 2004;139:288-294; discussion 295

43 Yeo CJ, Cameron JL, Lillemoe KD, et al: Does prophylactic octreotide decrease the rates of pancreatic fistula and other complications after pancreaticoduodenectomy? Results of a prospective randomized placebo-controlled trial. Ann Surg 2000;232:419-429.

44 Allen PJ: Pasireotide for postoperative pancreatic fistula. N Engl J Med 2014;371:875-876.

45 Schlitt HJ, Schmidt U, Simunec D, et al: Morbidity and mortality associated with pancreatogastrostomy and pancreatojejunostomy following partial pancreatoduodenectomy. $\mathrm{Br}$ J Surg 2002;89:1245-1251.
46 Heintges T, Lüthen R, Niederau C: Inhibition of exocrine pancreatic secretion by somatostatin and its analogues. Digestion 1994; 55(suppl 1):1-9.

47 Klempa I, Schwedes U, Usadel KH: [Prevention of postoperative pancreatic complications following duodenopancreatectomy using somatostatin]. Chirurg 1979;50:427-431.

48 Bruns C, Lewis I, Briner U, Meno-Tetang G, Weckbecker G: SOM230: a novel somatostatin peptidomimetic with broad somatotropin release inhibiting factor (SRIF) receptor binding and a unique antisecretory profile. Eur J Endocrinol 2002;146:707-716.

49 Facy O, Chalumeau C, Poussier M, Binquet C, Rat $\mathrm{P}$, Ortega-Deballon P: Diagnosis of postoperative pancreatic fistula. Br J Surg 2012;99: 1072-1075.

50 Bassi C, Dervenis C, Butturini G, et al: Postoperative pancreatic fistula: an international study group (ISGPF) definition. Surgery 2005; 138:8-13.

51 Balzano G, Zerbi A, Capretti G, Rocchetti S, Capitanio V, Di Carlo V: Effect of hospital volume on outcome of pancreaticoduodenectomy in Italy. Br J Surg 2008;95:357-362.

52 de Wilde RF, Besselink MG, van der Tweel I, et al: Impact of nationwide centralization of pancreaticoduodenectomy on hospital mortality. Br J Surg 2012;99:404-410.

53 Ansorge C, Strömmer L, Andrén-Sandberg Å, Lundell L, Herrington MK, Segersvärd R: Structured intraoperative assessment of pancreatic gland characteristics in predicting complications after pancreaticoduodenectomy. Br J Surg 2012;99:1076-1082.

54 Strasberg SM, Drebin JA, Mokadam NA, et al: Prospective trial of a blood supply-based technique of pancreaticojejunostomy: effect on anastomotic failure in the Whipple procedure. J Am Coll Surg 2002;194:746-758; discussion 759-760.
Somatostatin Analogues for

Pancreaticoduodenectomy 